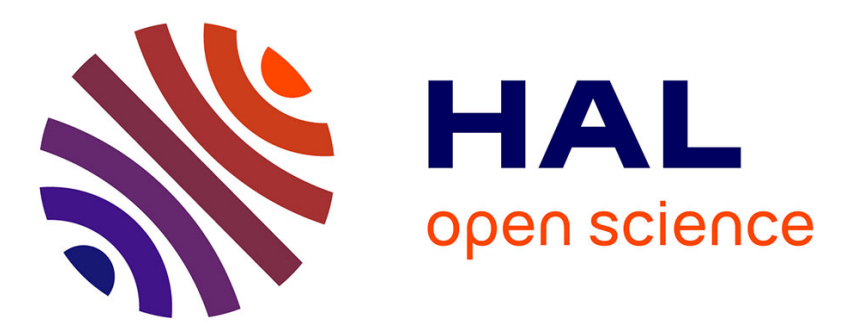

\title{
Epoxy/amine reactive systems for composites materials and their thermomechanical properties
}

\author{
Abbas Tcharkhtchi, Fabien Nony, Sofiane Khelladi, Joseph Fitoussi, Sedigheh
}

Farzaneh

\section{- To cite this version:}

Abbas Tcharkhtchi, Fabien Nony, Sofiane Khelladi, Joseph Fitoussi, Sedigheh Farzaneh. Epoxy/amine reactive systems for composites materials and their thermomechanical properties. Advances in Composites Manufacturing and Process Design, Elsevier, pp.269-296, 2015, 978-178242320-1;978178242307-2. 10.1016/B978-1-78242-307-2.00013-0 . hal-02568821

\section{HAL Id: hal-02568821 \\ https://hal.science/hal-02568821}

Submitted on 10 May 2020

HAL is a multi-disciplinary open access archive for the deposit and dissemination of scientific research documents, whether they are published or not. The documents may come from teaching and research institutions in France or abroad, or from public or private research centers.
L'archive ouverte pluridisciplinaire HAL, est destinée au dépôt et à la diffusion de documents scientifiques de niveau recherche, publiés ou non, émanant des établissements d'enseignement et de recherche français ou étrangers, des laboratoires publics ou privés. 


\title{
Epoxy/amine reactive systems for composites materials and their thermomechanical properties
}

\author{
A. Tcharkhtchi ${ }^{1}$, F. Nony ${ }^{2}$, S. Khelladi ${ }^{1}$, J. Fitoussi ${ }^{1}$, S. Farzaneh ${ }^{1}$ \\ ${ }^{1}$ Arts et Métiers ParisTech, Paris, France; ${ }^{2}$ CEA le Ripault, Monts, France
}

\subsection{Introduction}

Polyepoxy has an exceptional place among the thermosets because of its wide range of applications, especially in manufacturing of composites-based polymers. It is the result of the reactions between epoxy resins and hardeners. The epoxy resins have a wide range of reactivity with multiple-choice type hardeners. In particular, epoxy resins cross-linked with amines hardeners have high glass transition temperatures of $150-250^{\circ} \mathrm{C}$. They also have excellent thermal stability and good chemical resistance. The variation in viscosity during their curing is closely related to the reaction mechanism between the epoxy groups and primary and secondary amine groups.

An abundant literature has been devoted to studying the cross-linking of epoxy/ amine in which different approaches and methods of monitoring are often considered.

In statistical methods, the distribution of the components during reaction may be predicted using the probability laws (Pascault et al., 2002). Miller et al. (Miller and Macosko, 1978, 1980; Miller et al., 1979) have presented the structural parameters such as molecular weight in function of the rate conversion. By combining statistical approaches with other combinatorial approaches, Matejka (2000) modeled the crosslinking of an epoxy system.

In the numerical approach, the evolution of the structure is determined by a calculation that takes into account the different physicochemical interactions. Quantifying these interactions is a major limitation of this approach. In the case of gel formation, it is necessary to incorporate the dynamics of the internal structure and physicochemical interactions of sol-gel, which is difficult work. Two simulation models are often encountered:

- The percolation model based on a fixed mesh as calculation support. This model does not take into account the mobility of species in the reaction, and it is often used in the vicinity of the gel point.

- The percolation model without fixed mesh or model of limited aggregation by diffusion (cluster-cluster model), which describes the growth of aggregates (clusters). But this method cannot describe the cross-linking of thermosets.

In kinetic methods, the description of the formation of 3D network is carried out via a mechanism that takes into account the basic steps of the involved reactions, such as inter- or intramolecular reactions. This mechanistic approach is used to describe more 
accurately the evolution of structure, taking into account the different parameters affecting the reaction such as the reactivity of chemical (Liu et al., 2004) groups, and the diffusion effect on the mobility of groups (Wise et al., 1997; Prolongo et al., 2003; Corezzi et al., 2010). Analytical or numerical solution of the resulting differential equations allows us to determine the concentrations of the various groups and to follow the progress of the reaction.

\subsection{Reactive epoxy/amine systems}

\subsubsection{Cross-linking mechanism}

The cross-linking mechanism of epoxy/amine resins is summarized by Figures 13.1 and 13.2.<smiles>CNCC(O)[14CH2]N</smiles>

(a)

$A_{1}$

$\mathrm{A}_{2}$

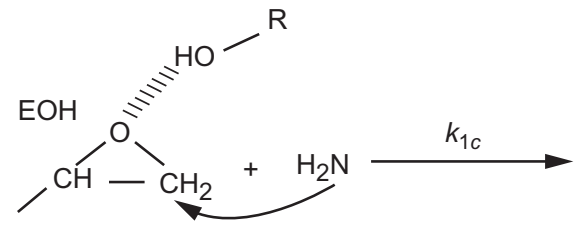

(b)

$A_{1}$<smiles>[R]O[NH2+]CC(C)O</smiles>

$\mathrm{A}_{2}$

Figure 13.1 Opening of epoxy cycle by primary amines with (a) and without (b) catalysts. Source: Smith (1961).<smiles>[R]N(C)CC(O)CCCCCOC(C)C</smiles>

(a)

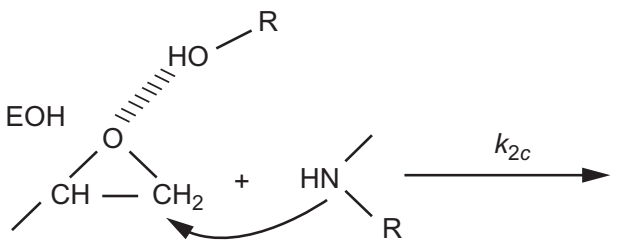

(b)

$\mathrm{A}_{2}$<smiles>[R]O[NH2+]N([R])CC(C)O</smiles>

$\mathrm{A}_{3}$

Figure 13.2 Opening of epoxy cycle by secondary amines with (a) and without (b) catalysts. Source: Horie et al. (1970). 


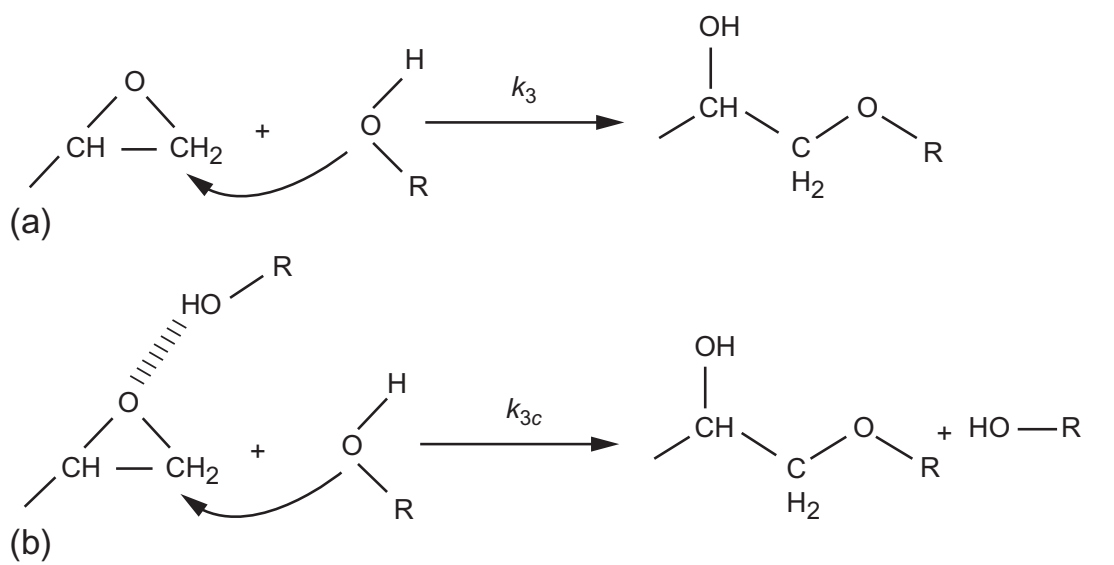

Figure 13.3 Esterification mechanism with (a) and without (b) catalyst.

Source: Mezzenga et al. (2000).

This mechanism was originally proposed by Smith (1961) and Horie et al. (1970). Activation of the opening of epoxy cycle is provided by the formation of complexes based on hydrogen bonds, particularly the association of the hydroxyl groups with epoxy that gives a complex of type (EOH) (Rozenberg, 1986; Flammersheim, 1998; Mezzenga et al., 2000), but protons of primary amine can also form such type of complexes.

Other types of proton donor impurity can catalyze the opening of epoxy cycle. Flammersheim (1998) considered the formation of three types of complexes (i.e., hydroxyl-epoxy, amine-epoxy, amine-hydroxyl) in a general cross-linking mechanism to model the experimental results (Figure 13.3), while the number of adjustable parameters was quite important (Riccardi et al., 2001).

The formation of the hydroxyl-epoxy complex (EOH) is the main effect of catalyzing the cross-linking reaction. Hydroxyl groups can be present in the structure of the reactive molecules and, simultaneously, they are the results of the opening of the epoxy ring; hence, the autocatalytic nature of the reaction of the catalyst.

The esterification reaction (Figure 13.3) may occur at high temperature; it is catalyzed by tertiary amines (Mezzenga et al., 2000), the result of the secondary amines reaction like in the case of tetradiglycidyl diaminodiphenylmethane (TGDDM). In the case of aromatic amines, the tertiary amines formed during reaction can not catalyze the homopolymerization of the epoxy groups at temperatures below $150{ }^{\circ} \mathrm{C}$ (Rozenberg, 1986). The esterification is a competitive reaction when the hardener (amine) has a low basicity like in the case of 4,4'-methylene bis (3-chloro-2,6-diethylaniline) (MCDEA) (Ramos et al., 2005).

\subsubsection{Cross-linking kinetic}

The mechanism of cross-linking of epoxy/amine system may be presented by the following reactions:

$$
\mathrm{E}+\mathrm{OH} \underset{k_{d}}{\stackrel{k_{f}}{\rightleftarrows}} \mathrm{E} \cdots \mathrm{OH}
$$




$$
\begin{aligned}
& \mathrm{E} \cdots \mathrm{OH}+\mathrm{A}_{1} \stackrel{k_{1 c}}{\longrightarrow} \mathrm{A}_{2}+2 \mathrm{OH} \\
& \mathrm{E} \cdots \mathrm{OH}+\mathrm{A}_{2} \stackrel{k_{2 c}}{\longrightarrow} \mathrm{A}_{3}+2 \mathrm{OH} \\
& \mathrm{E}+\mathrm{A}_{1} \stackrel{k_{1}}{\longrightarrow} \mathrm{A}_{2}+2 \mathrm{OH} \\
& \mathrm{E}+\mathrm{A}_{2} \stackrel{k_{2}}{\longrightarrow} \mathrm{A}_{3}+2 \mathrm{OH}
\end{aligned}
$$

where $A_{1}, A_{2}, A_{3}, E$, and $E O H$ are primary amine, secondary amine, tertiary amine, epoxy, and hydroxyl-epoxy complex, respectively.

The differential equations derived from the above reaction may be presented as follows:

$$
\begin{aligned}
& \frac{\mathrm{d}[\mathrm{E}]}{\mathrm{d} t}=-k_{1}\left[\mathrm{~A}_{1}\right][\mathrm{E}]-k_{2}\left[\mathrm{~A}_{2}\right][\mathrm{E}]-k_{1 c}\left[\mathrm{~A}_{1}\right][\mathrm{E}][\mathrm{OH}]-k_{2 c}\left[\mathrm{~A}_{2}\right][\mathrm{E}][\mathrm{OH}] \\
& \frac{\mathrm{d}\left[\mathrm{A}_{1}\right]}{\mathrm{d} t}=-k_{1}\left[\mathrm{~A}_{1}\right][\mathrm{E}]-k_{1 c}\left[\mathrm{~A}_{1}\right][\mathrm{E}][\mathrm{OH}] \\
& \frac{\mathrm{d}\left[\mathrm{A}_{2}\right]}{\mathrm{d} t}=k_{1}\left[\mathrm{~A}_{1}\right][\mathrm{E}]-k_{2}\left[\mathrm{~A}_{2}\right][\mathrm{E}]+k_{1 c}\left[\mathrm{~A}_{1}\right][\mathrm{E}][\mathrm{OH}]-k_{2 c}\left[\mathrm{~A}_{2}\right][\mathrm{E}][\mathrm{OH}] \\
& \frac{\mathrm{d}\left[\mathrm{A}_{3}\right]}{\mathrm{d} t}=k_{2}\left[\mathrm{~A}_{2}\right][\mathrm{E}]+k_{2 c}\left[\mathrm{~A}_{2}\right][\mathrm{E}][\mathrm{OH}] \\
& \frac{\mathrm{d}[\mathrm{OH}]}{\mathrm{d} t}=k_{1}\left[\mathrm{~A}_{1}\right][\mathrm{E}]+k_{2}\left[\mathrm{~A}_{2}\right][\mathrm{E}]+k_{1 c}\left[\mathrm{~A}_{1}\right][\mathrm{E}][\mathrm{OH}]+k_{2 c}\left[\mathrm{~A}_{2}\right][\mathrm{E}][\mathrm{OH}]
\end{aligned}
$$

The resolution of these equations gives the evolution of different chemical groups during cross-linking reactions. A simplified model has been proposed by Paz-Abuin et al. (1997a) to determine the reactivity ratio, $r$ :

$$
\frac{\left[\mathrm{A}_{1}\right]}{\left[\mathrm{A}_{2}\right]}=\frac{\left(k_{2}+k_{2 c}[\mathrm{OH}]\right)}{\left(k_{1}+k_{1 c}[\mathrm{OH}]\right)}=r
$$

Table 13.1 shows the reactivity ratio of different epoxy/amine systems. It can be seen that the reactivity ratio depends on the nature of epoxy system. It depends also on the temperature.

\subsubsection{Evolution of rheology of the reactive system during cross-linking}

The changes in viscosity over time are controlled by changing the macromolecular structure of the reactive mixture. Through this evolution of structure and physical properties, two main phenomena can be distinguished: gelation and vitrification. 
Table 13.1 Numerical values of reactivity ratio, $r$, determined in the case of DGEBA cross-linked with different amine hardeners

\begin{tabular}{|c|c|c|c|c|}
\hline System & $\begin{array}{l}\text { Temperature } \\
\text { (K) }\end{array}$ & $\begin{array}{l}\text { Activity } \\
\text { (r) }\end{array}$ & $\begin{array}{l}\text { Experimental } \\
\text { methods }\end{array}$ & Reference \\
\hline DGEBA/DDS & $413-453$ & 0.5 & $\mathrm{UV}-\mathrm{V}$ is & Mijovic et al. (1992) \\
\hline DGEBA/DDS & 450 & 0.1 & FTIR & Mijovic et al. (1992) \\
\hline DGEBA/TMAB & $373-433$ & $0.16-0.33$ & FTIR & Mijovic et al. (1992) \\
\hline DGEBA/MDA & $333-423$ & $0.08-0.14$ & $\begin{array}{l}\text { Chemical } \\
\text { titration }\end{array}$ & Mijovic et al. (1992) \\
\hline DGEBA/HMDA & 323 & $0.25-0.50$ & $\begin{array}{l}\text { Chemical } \\
\text { titration }\end{array}$ & Charlesworth (1980) \\
\hline DGEBA/HMDA & 323 & $0.78-0.86$ & GPC & Charlesworth (1980) \\
\hline DGEBA/DDS & 433 & 0.23 & FT-NIR & Liu et al. (2004) \\
\hline DGEBA/DETDA & 433 & 0.19 & FT-NIR & Liu et al. (2004) \\
\hline DGEBA/DMTDA & 433 & 0.42 & FT-NIR & Liu et al. (2004) \\
\hline DGEBA/MCDEA & 408 & 0.33 & SEC & $\begin{array}{l}\text { Girard-Reydet et al. } \\
\text { (1995) }\end{array}$ \\
\hline DGEBA/MDEA & 408 & 0.33 & SEC & $\begin{array}{l}\text { Girard-Reydet et al. } \\
\text { (1995) }\end{array}$ \\
\hline DGEBA/DDS & 408 & 0.21 & SEC & $\begin{array}{l}\text { Girard-Reydet et al. } \\
\text { (1995) }\end{array}$ \\
\hline
\end{tabular}

\subsubsection{Gelation}

The gel is characterized by increasing of the molecular weight $\left(M_{\mathrm{w}}\right)$ and formation of network structure. The evolution of the rheological properties of a reactive system during the cross-linking reaction may be represented schematically by Figure 13.4. The zero shear viscosity $\left(\eta_{0}\right)$ tends to infinity at gel point, where the elastic properties, represented by the elastic modulus $\left(G^{\prime}\right)$, begin to appear. Before the gel point, the viscous properties are represented by loss modulus $\left(G^{\prime \prime}\right)$ (Kroutilova et al., 2006;

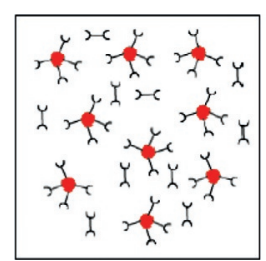

(a)

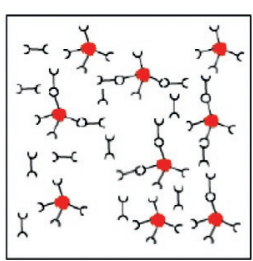

(b)

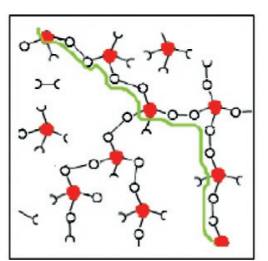

(c)

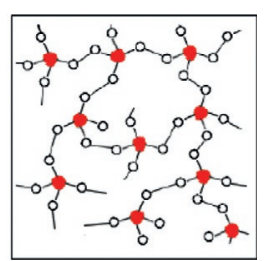

(d)

Figure 13.4 Chemical structure evolution during cross-linking of a reactive system: (a) resin and hardener; (b) linear/branched oligomers; (c) sol/gel transition; (d) 3D network.

Source: Mounif et al. (2008). 


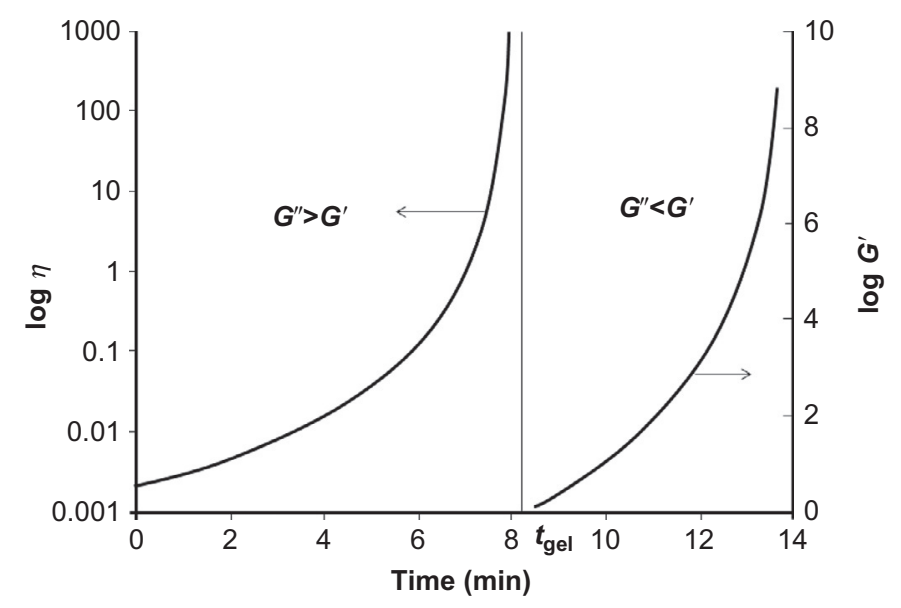

Figure 13.5 Variation of the viscosity and the elastic modulus during the cross-linking of a thermoset.

Source: Kroutilova (2006).

Figure 13.5). The rheological analysis, in dynamic mode, allows characterizing the system in both pregel and postgel phases; that is, from liquid state to full cross-linking.

Several rheological criteria were considered to determine the gel point. At this point

(i) elastic properties (elastic modulus) begin to appear,

(ii) zero shear viscosity $\eta_{0}$ diverges to infinite,

(iii) loss modulus $\left(G^{\prime \prime}\right)$ and storage modulus $\left(G^{\prime}\right)$ values are equal,

(iv) loss factor $(\tan \delta)$ is the same for different frequencies.

Halley (Tajima and Crozier, 1988) compared different criteria and showed that the criterion of loss factor is the most reliable.

\subsubsection{Vitrification}

Vitrification takes place when $T_{\mathrm{g}}$ of reactive system reaches the cross-linking isothermal temperature $\left(T_{\text {iso }}\right)$. This is a reversible change of the viscous liquid state to glassy solid state for nongelled system or to cross-linked glassy state for gelled system. Study of variation of $T_{\mathrm{g}}$ as a function of the conversion rate, $x$ on one hand, and the evolution of $x$ as function of time, on the other hand, permit us to determine the time of vitrification, $t_{\mathrm{vit}}$. The vitrification decelerates the cross-linking reaction because of decreasing of molecular chains mobility in glassy state.

The relationship between the conversion rate and the glass transition temperature was the subject of different research work. Between different models, DiBenedetto's equation (Equation 13.12), modified by Pascault and Williams (1990), is one the most frequently used. 


$$
T_{\mathrm{g}}=T_{\mathrm{g} 0}+\frac{\left(T_{\mathrm{g} \infty}-T_{\mathrm{g}}\right) \lambda x}{1-(1-\lambda) x}
$$

where $T_{\mathrm{g} 0}$ and $T_{g \infty}$ are the glass transition temperature at initial $(x=0)$ and final $(x=1)$ states, respectively, and $\lambda$ is an adjustable parameter between 0 and 1.

Knowing the conversion rate for which $T_{\mathrm{g}}=T_{\mathrm{iso}}$, and the analytical expression of the cross-linking reaction rate, determined by the conversion rate, we can calculate the time of vitrification by the following equation (Aizpurua et al., 2000; Enns and Gillham, 1983):

$$
\frac{\mathrm{d} x}{\mathrm{~d} t}=k f(x) \Rightarrow t_{\mathrm{vit}}=\frac{1}{k} \int_{0}^{x_{\mathrm{vit}}} \frac{\mathrm{d} x}{f(x)}
$$

\subsubsection{Time-temperature-transformation diagram}

The time-temperature-transformation (TTT) diagram (Enns and Gillham, 1983; Mounif et al., 2008) is a very useful tool for determination of the processing area of thermoset polymers (Figure 13.6). This diagram can identify the required time of different phenomena such as vitrification or gelation during isothermal cross-linking reaction. On this diagram, three characteristic temperatures can be distinguished:

- $T_{\mathrm{g} 0}$ is the glass transition temperature of the initial mixture; below this temperature the system does not react and can be stored for a long period.

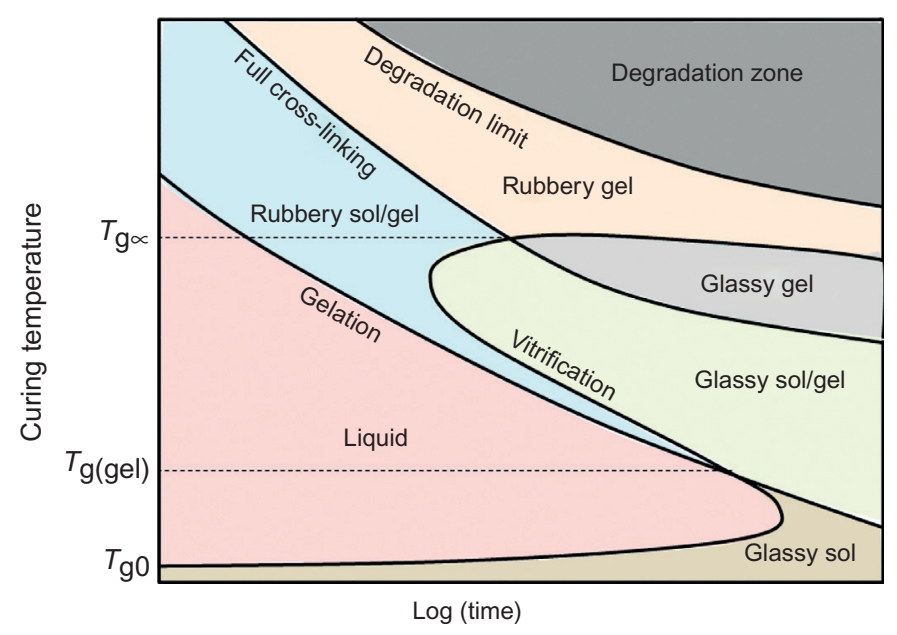

Figure 13.6 The theoretical diagram time-temperature-transformation (TTT) (Enns and Gillham, 1983).

Source: Enns and Gillham (1983). 
- $T_{\mathrm{g}(\mathrm{gel})}$ is the temperature corresponding to intersection of two curves: gelation and vitrification.

- $T_{\propto}$ is the glass transition temperature of $100 \%$ cross-linked system.

For the isothermal cross-linking temperatures above $T_{\mathrm{g}(\mathrm{gel})}$ and below $T_{\mathrm{g} \propto}$, the system gels before vitrifying; however, the cross-linking is incomplete because the glass transition temperature of the system (sol-gel rubber) reaches the isothermal curing temperature; $T_{\text {iso }}=T_{\mathrm{g}}$.

The full cross-linking $(x=1)$ requires a curing temperature higher than $T_{\mathrm{g} \propto}$; but this is not always possible due to the degradation of the reactive system. In general, the effect of the exothermal phenomenon (self-heating) of the reaction is not negligible, especially in the case of thick samples when the reaction rate is greater than the rate of heat dissipation. In this case, the temperature in the sample can be greater than the curing temperature, which eventually leads to $100 \%$ of cross-linking; even the curing temperature is below $T_{\mathrm{g} \propto}$.

\subsubsection{Rheokinetic models}

Rheochemistry is the study of the evolution of rheology of the reactive system (e.g., viscosity) during polymerization (Mounif et al., 2010). Generally, the viscosity is a function of temperature $(T)$, conversion rate $(x)$, and shear rate $(\dot{\gamma})$.

\subsubsection{Effect of temperature}

Temperature dependence of viscosity was modeled by two main approaches: Arrhenius law (Roller, 1986) and Williams-Landel-Ferry (WLF) law (Tajima and Crozier, 1986).

- The Arrhenius equation relates the viscosity and temperature according to Equation (13.14).

$$
\eta(T)=\eta_{\infty} \mathrm{e}^{E_{\eta} / R T}
$$

where $E_{\eta}$ is the activation energy, $\eta_{\infty}$ is the viscosity at $T=\propto$.

- The WLF equation (1955) is based on the theory of free volume:

$$
\operatorname{Ln} \frac{\eta}{\eta\left(T_{\mathrm{g}}\right)}=-\frac{C_{1}\left(T-T_{\mathrm{g}}\right)}{C_{2}+\left(T-T_{\mathrm{g}}\right)}
$$

where $C_{1}$ and $C_{2}$ are two constants independent of temperature; $T_{\mathrm{g}}$, glass transition temperature, is considered as reference temperature, and $\eta\left(T_{\mathrm{g}}\right)$ is the viscosity at this temperature.

As the glass transition temperature varies with cross-linking conversion rate, WLF equation has been modified in order to consider this evolution (Wang et al., 1997; Mijovic, 1989; Dai-Soo Lee, 1987; Tajima and Crozier, 1988; Chiou and Letton, 1992). It is supposed that $C_{1}$ and $C_{2}$ are not constant but depend to the temperature. 


\subsubsection{Effect of cross-linking}

In the case of linear polymer, the viscosity is a function of molecular weight according to the following equations:

$$
\eta=K\left(\bar{M}_{\mathrm{w}}\right)^{a} \text { with }\left\{\begin{array}{l}
a=1 \text { when } \bar{M}_{\mathrm{w}}<\bar{M}_{\mathrm{c}} \\
a=3.4 \text { when } \bar{M}_{\mathrm{w}}>\bar{M}_{\mathrm{c}}
\end{array}\right.
$$

$\bar{M}_{\mathrm{c}}$ : critical molecular weight where the entanglement density is zero.

The problem is more complicated for branched and cross-linked macromolecules. In these cases, the relationship between viscosity and molecular weight is not very simple, especially because of the gelation and formation of network structure.

Other models have been proposed to show the dependence of viscosity to the conversion rate of cross-linking reaction (Bidstrup and Macosko, 1990; Bonnet et al., 1999; Zimm and Stockmayer, 2004; Dušek, 1986; Valles and Macosko, 1979; Macosko, 1985). Mijovic and Ott (1989) proposed a model to show the relationship between viscosity $(\eta)$ and molar mass $M_{\mathrm{w}}$ for TGDDM/4,4'diaminodiphenyl sulfone (DDS) system and Macosko (Lipshitz and Macosko, 1976) for polyurethane.

Enns (Dušek, 1986) had used a model by combining the effect of molecular weight $M_{\mathrm{w}}$ and temperature using both WLF equation and Arrhenius model:

$$
\operatorname{Ln}(\eta)=\operatorname{Ln}\left(\eta_{\infty}\right)+s \operatorname{Ln}\left(\bar{M}_{\mathrm{w}}\right)+\frac{E_{\eta}}{R T_{0}}-\left(\frac{C_{1}\left(T-T_{0}\right)}{C_{2}+\left(T-T_{0}\right)}\right)
$$

with $T_{0}=T_{\mathrm{g}}+50$ (WLF) when $T<T_{\mathrm{g}}+50$ and $T=T_{0}$ (Arrhenius) when $T>T_{\mathrm{g}}+50$. The model proposed by Castro and Macosko (1980) was often used in the case of polyurethanes where gel point distance in terms of conversion $\left(x_{\mathrm{gel}}-x\right)$ is the main parameter:

$$
\frac{\eta}{\eta_{0}}=\left(\frac{x_{\mathrm{gel}}}{x_{\mathrm{gel}}-x}\right)^{f(x, T)}
$$

where $\eta_{0}$ is the initial viscosity, $x_{\text {gel }}$ is the conversion rate at gel point, $f(x, T)$ is assumed to be a linear function of $x$ (at constant temperature): $f(x)=A x+B$, with $A$ and $B$ constants $(A=4, B=-2)$ (Castro and Macosko, 1982). Macosko (1985) used this equation to model the viscosity of DGEBA/isophorone di-amine (IPD) system.

\subsubsection{Effect of shear}

The effect of shear rate on viscosity can be neglected and the behavior of the reactive system can be considered Newtonian, assuming the validity of the rule of Cox-Merz (Cox and Merz, 1958). As can be seen in Figure 13.7, the viscosity measured at various shear rates is the same. 
Figure 13.7 Viscosity of DGEBA/DDS46 reaction mixture at different shear rates.

Source: Bidstrup and Macosko (1990).

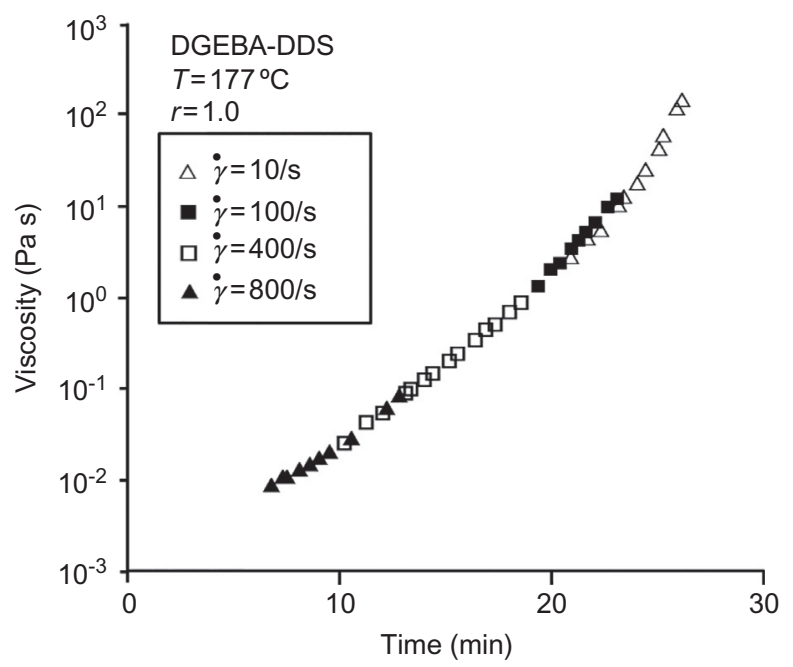

\subsection{Epoxy/amine systems}

The epoxy/amine systems are classified according to their chemical structures. Epoxy is an aromatic molecule but amine may be an aromatic or aliphatic molecule. Polyepoxy is a thermoset polymer resulting from the cross-linking reaction between an epoxy (prepolymer) and an amine molecule or other hardeners.

\subsubsection{Epoxy prepolymers}

The epoxy prepolymer (olygomer) is the main component of the reactive system. These epoxys can be di (DGEBA), tri (TGAP), or tetra (TGDDM) functional molecules. Between different epoxy molecules, the compounds based on diglycidyl ether of bisphenol A (DGEBA) are widely used. Depending on the degree of polymerization ( $n$ ), it may be liquid $(n<1)$ or solid $(n>1.5)$. The epoxy polymers can react with different types of chemical group, such as amines, anhydrides, isocyanates, phenol, and others.

\subsubsection{Amine hardeners}

According to their chemical structures, the amine hardeners can be classified into three categories:

(i) The aliphatic amines (i.e., hexamethylene diamine (HMDA)): their reaction with epoxy groups is very fast because of their high reactivity even at room temperature.

(ii) Cycloaliphatic amines (i.e., IPD): they are less toxic than the aliphatic amine hardeners.

(iii) Aromatic amines (i.e., DDS): the phenyl rings introduce large enough rigidity (and thus $T_{\mathrm{g} \infty}$ ), which explains that these amines hardeners are a suitable choice for applications that need high thermal stability. 


\subsubsection{Characteristics of the main epoxy/amine systems}

Literature data on DGEBA/amine systems listed in Tables 13.2 and 13.3 are represented by Figure 13.8 in the form of $T_{\text {iso }}=f\left(t_{\mathrm{gel}}\right)$. The same shape of the curves $T_{\text {iso }}=f\left(t_{\text {gel }}\right)$ for various systems was modeled by an exponential law. Different criteria gel was considered to determine the gel point. It was considered that loss factor is a rheological criterion for selecting gel point (Table 13.4).

\subsection{Thermomechanical behavior of epoxy/amine systems}

\subsubsection{Effect of temperature on stress-strain curve}

Polyepoxies display generally high toughness (Chang and Brittain, 1982; Kinloch, 1985; Lemay and Kelley, 1986; Urbaczewski-Espuche et al., 1991; Grillet et al., 1991; Fischer, 1988), but they remain, in most of the cases, less ductile than thermoplastics of comparable $T_{\mathrm{g}}$ value; for instance, polycarbonate or polysulphone. Thermosets are often brittle, but it is licit to claim that brittleness is a general property of these polymers? To answer this question, it is first important to remark that certain thermoplastics (e.g., polystyrene) are very brittle. From a detailed investigation on the relationships between structure and fracture behavior in linear polymers, Wu showed that the thermoplastic polymers displaying the highest ductility and toughness are the most densely physically cross-linked ones (cross-linking being due to entanglement in these cases) (Wu, 1992). In fact, $\mathrm{Wu}$ demonstrates that cross-link density is linked to chain tortuosity ( $\mathrm{Wu}, 1989)$, the latter being related to the level of the conformational energy barriers (de Gennes, 1991). Thus, there is a key difference between linear and cross-linked polymers: in the former ones, the cross-link density is a consequence of the conformational structure, whereas in the latter ones, both characteristics are independent as the cross-link density is first determined by the chemistry of the systems. However, there is no reason to exclude the hypothesis of existence of networks (with covalent cross-links), in which the conformational behavior would be favorable to ductility, according to Wu's theory. In this case, it would be abusive to claim that a given material is brittle because it is densely cross-linked. On the other hand, the fracture behavior of the thermosets around the ambient temperature cannot be interpreted in terms of limited extensibility of network segments linked to the high cross-link density. As a matter of fact, these materials display relatively high draw ratios when they are stretched at temperature close to $T_{\mathrm{g}}$. The tensile tests on DGEBA/DDS system have shown that this polymer, with a $T_{\beta}=-50{ }^{\circ} \mathrm{C}$ and $T_{\alpha}=220^{\circ} \mathrm{C}$, displays yielding and plastic deformation above approximately $120^{\circ} \mathrm{C}$ (Figure 13.9; Tcharkhtchi et al., 1999).

The maximum stress $\sigma_{\mathrm{M}}$ and the elongation at break versus temperature (Figure 13.10) show two fracture regimes: brittle and plastic regimes separated by a critical temperature $T_{\mathrm{BP}}$.

- Brittle regime is characterized by high maximum stress and low elongation at break. 
Table 13.2 Acronyms of amines hardeners

\begin{tabular}{|l|l|l|}
\hline Amine hardeners & Acronyms & Common name \\
\hline Diethylene triamine & DTA & \\
3-Aminomethyl- & IPD & Isophorone diamine \\
3,5,5-trimethylcyclohexylamine & & \\
Bis( $p$-aminocyclohexy1) methane & PACM & \\
4,4'-Diaminodiphenylsulfone & DDS & \\
4,4'-Diaminodiphenylmethane & DDM & MDA (4,4'-methylène dianiline $)$ \\
4,9-Dioxa 1,12-dodecanediamine & 4D & \\
4,4'-Diamino- & 3 DCM & \\
3,3'-dimethyldicyclohexylmethane & MDEA & \\
$4,4^{\prime}$-Methylenebis [2,6-diethylaniline] & MCDEA & \\
$4,4^{\prime}$-Methylenebis [3-chloro & $m$-XDA & \\
2,6-diethylaniline] & $m$-PDA & \\
$m$-Xylylenediamine & TMAP & \\
$m$-Phenylenediamine & D400 & Jeffamine \\
Trimethylene glycol di- $p$ - & HMDA & \\
aminobenzoate & Polyoxypropylene & \\
Hexamethylenediamine &
\end{tabular}

Table 13.3 Acronyms of epoxy resins

\begin{tabular}{|l|l|l|}
\hline Epoxy resins & Acronymes & Common name \\
\hline Diglycidylether of biphenol A & DGEBA & \\
Diglycidylether of 1,4-butanediol & DGEBU & \\
Tetraglycidyl $4,4^{\prime}$-diaminodiphenyl methane & TGDDM & \\
Triglycidyl $p$-aminophenol & TGAP & \\
\hline
\end{tabular}

Figure 13.8 Curves of gelation $\left(T_{\text {iso }}=f\left(t_{\text {gel }}\right)\right)$ for different epoxy/amine systems.

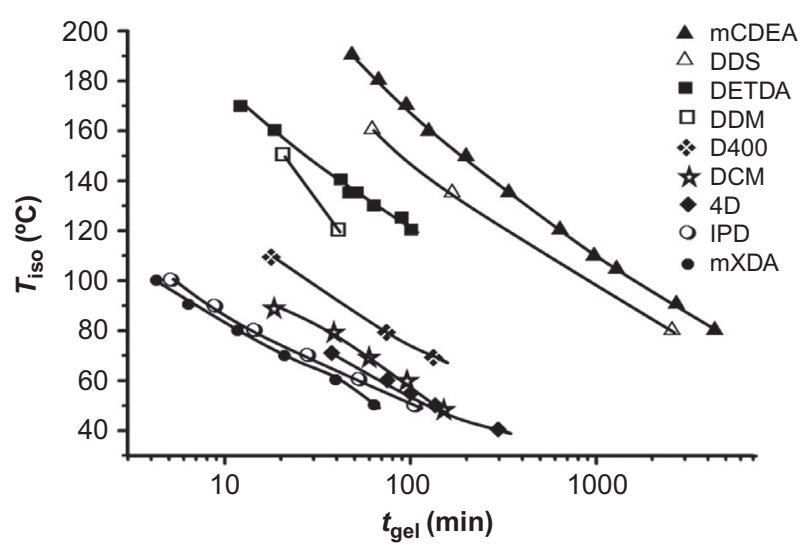


Table 13.4 The main characteristics of the common epoxy/amine systems

\begin{tabular}{|c|c|c|c|c|c|c|c|}
\hline $\begin{array}{l}\text { System } \\
\text { reactive }\end{array}$ & $\left(T_{\mathrm{g}}\right)_{0}\left({ }^{\circ} \mathrm{C}\right)$ & $\left(T_{\mathrm{g}}\right)_{\mathrm{gel}}\left({ }^{\circ} \mathrm{C}\right)$ & $\left(\boldsymbol{T}_{\mathbf{g}}\right)_{\propto}\left({ }^{\circ} \mathbf{C}\right)$ & $\begin{array}{l}\left(T_{\mathrm{g}}\right)_{\text {iso }} \\
\left({ }^{\circ} \mathbf{C}\right)\end{array}$ & $t_{\text {gel }}(\min )$ & $x_{\text {gel }}(\min )$ & References \\
\hline DGEBA/DDS & $\begin{array}{l}-7 \\
\text { (Smith, } \\
1961) \\
-7 \text { (Paz- } \\
\text { Abuin } \\
\text { et al., } \\
\text { 1997b) }\end{array}$ & $\begin{array}{l}81 \\
60 \text { (Paz-Abuin } \\
\text { et al., 1997b) }\end{array}$ & $\begin{array}{l}209 \\
214 \text { (Aizpurua } \\
\text { et al., 2000) }\end{array}$ & $\begin{array}{l}100 \\
120 \\
140 \\
80 \\
135 \\
160\end{array}$ & $\begin{array}{l}810\left(\eta=10^{4},\right. \\
\text { Matejka and } \\
\text { Dusek, 1989) } \\
365 \\
165 \\
2500(x=0.6) \\
\text { (Paz-Abuin et al., } \\
1997 b) \\
165(x=0.6) \\
\text { (Paz-Abuin et al., } \\
1997 b) \\
62(x=0.6)(\text { Paz- } \\
\text { Abuin et al., } \\
1997 b)\end{array}$ & $\begin{array}{l}0.65 \\
\text { (Chiou and } \\
\text { Letton, } \\
1992 \text { ) } \\
0.61 \\
\text { (Miller } \\
\text { and } \\
\text { Macosko, } \\
1980 \text { ) }\end{array}$ & $\begin{array}{l}\text { Miller and Macosko (1980), Paz- } \\
\text { Abuin et al. (1997a,b), Matejka and } \\
\text { Dusek (1989), and Chiou and Letton } \\
\text { (1992) }\end{array}$ \\
\hline $\begin{array}{l}\text { DGEBA/ } \\
\text { 3DCM }\end{array}$ & $\begin{array}{l}-32 \\
\text { (Smith, } \\
1961)\end{array}$ & & 183 & $\begin{array}{l}50 \\
60 \\
70 \\
80 \\
90\end{array}$ & $\begin{array}{l}146\left(G^{\prime}=G^{\prime \prime}\right) \\
\text { (Miller and } \\
\text { Macosko, } 1978) \\
89.5\left(G^{\prime}=G^{\prime \prime}\right) \\
57.5\left(G^{\prime}=G^{\prime \prime}\right) \\
38\left(G^{\prime}=G^{\prime \prime}\right) \\
18\left(G^{\prime}=G^{\prime \prime}\right)\end{array}$ & & $\begin{array}{l}\text { Miller and Macosko (1978) and } \\
\text { Smith (1961) }\end{array}$ \\
\hline DGEBA/4D & & & $\begin{array}{l}12 \text { (Horie et al., } \\
1970)\end{array}$ & $\begin{array}{l}50 \\
55\end{array}$ & $\begin{array}{l}136 \text { (Mezzenga } \\
\text { et al., 2000) } \\
97.3 \text { (Mezzenga }\end{array}$ & & Horie et al. (1970) \\
\hline
\end{tabular}


Table 13.4 Continued

\begin{tabular}{|c|c|c|c|c|c|c|c|}
\hline $\begin{array}{l}\text { System } \\
\text { reactive }\end{array}$ & $\left(T_{\mathrm{g}}\right)_{0}\left({ }^{\circ} \mathrm{C}\right)$ & $\left(T_{\mathrm{g}}\right)_{\text {gel }}\left({ }^{\circ} \mathrm{C}\right)$ & $\left(T_{\mathbf{g}}\right)_{\propto}\left({ }^{\circ} \mathbf{C}\right)$ & $\begin{array}{l}\left(\boldsymbol{T}_{\mathrm{g}}\right)_{\text {iso }} \\
\left({ }^{\circ} \mathbf{C}\right)\end{array}$ & $t_{\text {gel }}(\min )$ & $x_{\text {gel }}(\min )$ & References \\
\hline $\begin{array}{l}\text { DGEBA/ } \\
\text { MCDEA }\end{array}$ & $\begin{array}{l}-17 \\
\text { (Paz- } \\
\text { Abuin } \\
\text { et al., } \\
\text { 1997b) }\end{array}$ & $\begin{array}{l}50 \text { (Paz-Abuin } \\
\text { et al., 1997b) }\end{array}$ & $\begin{array}{l}\text { 177(Paz-Abuin } \\
\text { et al., 1997b) }\end{array}$ & $\begin{array}{l}80 \\
135 \\
160 \\
80 \\
90 \\
105 \\
110 \\
120 \\
135 \\
150 \\
160 \\
170 \\
180 \\
190\end{array}$ & $\begin{array}{l}\text { et al., 2000) } \\
72.8 \text { (Mezzenga } \\
\text { et al., 2000) } \\
36.8 \text { (Mezzenga } \\
\text { et al., 2000) } \\
4300 \text { ( } x=0.6) \\
\text { (Aizpurua et al., } \\
2000) \\
300 \text { ( } x=0.6) \\
\text { (Aizpurua et al., } \\
2000) \\
120 \text { ( } x=0.6) \\
\text { (Aizpurua et al., } \\
2000) \\
4250 \text { (Horie } \\
\text { et al., 1970) } \\
2639 \text { (Horie } \\
\text { et al., 1970) } \\
1250 \text { (Horie } \\
\text { et al., 1970) } \\
953 \text { (Horie et al., } \\
1970 \text { ) } \\
632 \text { (Horie et al., } \\
1970 \text { ) } \\
333 \text { (Horie et al., } \\
1970 \text { ) }\end{array}$ & $\begin{array}{l}0.56 \\
\text { (Mijovic, } \\
1989, \\
G^{\prime}=G^{\prime \prime} \text { ) }\end{array}$ & $\begin{array}{l}\text { Horie et al. (1970) and Paz-Abuin } \\
\text { et al. (1997b) }\end{array}$ \\
\hline
\end{tabular}




\begin{tabular}{|c|c|c|c|c|c|c|c|}
\hline & & & & & $\begin{array}{l}192 \text { (Horie et al., } \\
1970 \text { ) } \\
123 \text { (Horie et al., } \\
1970 \text { ) } \\
92 \text { (Horie et al., } \\
1970 \text { ) } \\
65.5 \text { (Horie et al., } \\
1970 \text { ) } \\
47 \text { (Horie et al., } \\
1970 \text { ) }\end{array}$ & & \\
\hline $\begin{array}{l}\text { DGEBA/ } \\
\text { D400 }\end{array}$ & & $\begin{array}{l}-9 \text { (Mijovic } \\
\text { et al., 1992) }\end{array}$ & & $\begin{array}{l}70 \\
80 \\
110\end{array}$ & $\begin{array}{l}131 \\
73.8(57, \text { Mijovic } \\
\text { et al., } 1992, \\
\left.G^{\prime}=G^{\prime \prime}\right) \\
17.7\end{array}$ & & $\begin{array}{l}\text { Mijovic (1989) and Mounif et al. } \\
\text { (2010) }\end{array}$ \\
\hline DGEBA/IPD & -43 & 25 & $\begin{array}{l}40 \text { (Mijovic } \\
\text { et al., 1992) }\end{array}$ & $\begin{array}{l}60 \\
70 \\
80 \\
90 \\
100\end{array}$ & $\begin{array}{l}68 \\
38 \\
22 \\
13.5 \\
8\end{array}$ & 0.61 & Cioffi et al. (2002) \\
\hline $\begin{array}{l}\text { TGDDM/ } \\
\text { DDM }\end{array}$ & -16 & & 153 & $\begin{array}{l}100 \\
110 \\
140\end{array}$ & $\begin{array}{l}34 \\
15 \\
3\end{array}$ & & Mezzenga et al. (2000) \\
\hline $\begin{array}{l}\text { TGDDM/ } \\
\text { DDS }\end{array}$ & & & & 160 & $\begin{array}{l}52 \text { (Paz-Abuin } \\
\text { et al., 1997a) }\end{array}$ & & $\begin{array}{l}\text { Miller and Macosko (1978) and } \\
\text { Kroutilova et al. (2006) }\end{array}$ \\
\hline $\begin{array}{l}\text { DGEBA/ } \\
\text { DETDA }\end{array}$ & -25 & & & & 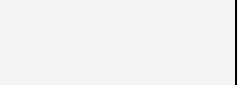 & & Aizpurua et al. (2000) \\
\hline $\begin{array}{l}\text { DGEBA/ } \\
\text { DDM }\end{array}$ & -16 & & 178 & $\begin{array}{l}80 \\
135\end{array}$ & $\begin{array}{l}105(x=0.6) \\
10(x=0.6)\end{array}$ & & Paz-Abuin et al. (1997b) \\
\hline $\begin{array}{l}\text { DGEBA/ } \\
\text { EDA }\end{array}$ & & 2 & 105 & 40 & $62\left(G^{\prime}=G^{\prime \prime}\right)$ & 0.4 & Mijovic et al. (1992) \\
\hline
\end{tabular}




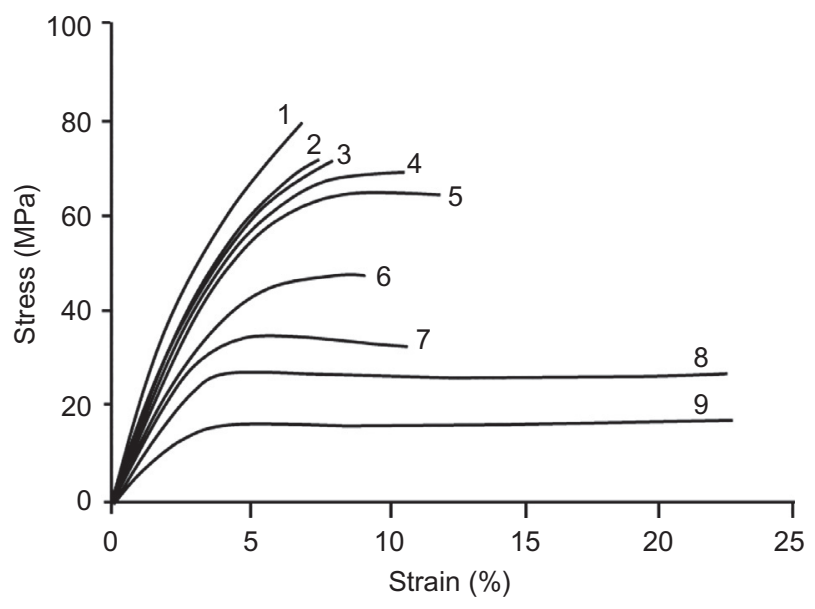

Figure 13.9 Tensile curves of DGEBA/DDS at the strain rate $2.77 \times 10^{-3} \mathrm{~s}^{-1}$ at different temperatures (Tcharkhtchi et al., 1999): (1) $20^{\circ} \mathrm{C}$, (2) $70{ }^{\circ} \mathrm{C}$, (3) $110{ }^{\circ} \mathrm{C}$, (4) $115{ }^{\circ} \mathrm{C}$, (5) $120{ }^{\circ} \mathrm{C}$, (6) $140{ }^{\circ} \mathrm{C}$, (7) $170{ }^{\circ} \mathrm{C}$, (8) $180{ }^{\circ} \mathrm{C}$, and (9) $200{ }^{\circ} \mathrm{C}$.

Source: Tcharkhtchi et al. (1999).

(a)
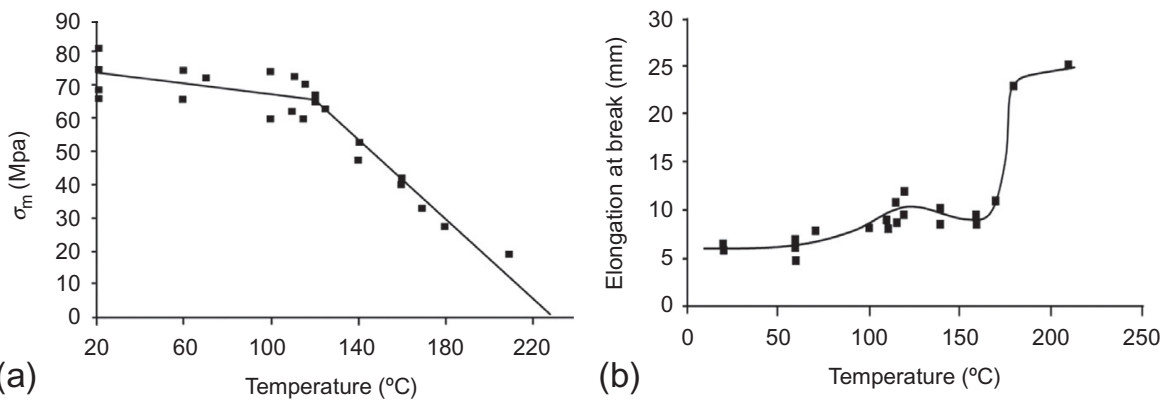

Figure 13.10 Maximum stress (a) and elongation at break (b) versus temperature for DGEBA/ DDS samples (strain rate $2.77 \times 10^{-3} \mathrm{~s}^{-1}$ ) (Tcharkhtchi et al., 1999).

Source: Tcharkhtchi et al. (1999).

- Plastic regime with high elongation at break. In this regime, the yield stress varies almost linearly with temperature according to the relationship established by Kambour (Kambour, 1983) for linear amorphous polymers:

$$
\sigma_{\mathrm{y}}=C\left(T_{\mathrm{g}}-T\right)
$$

where $C$ is a constant independent of $T_{\mathrm{g}}$ at least in a first approximation. According to this relationship, $\sigma_{\mathrm{y}}$ is an increasing function of $T_{\mathrm{g}}$ in a given structural series, except for unexpected very large variations of $C$. 
If, then, the fracture behavior is considered as resulting from the competition between a "brittle" process, in which the ultimate stress is almost independent of temperature, and a "plastic" process in which the yield stress is a decreasing function of temperature (as shown in Figure 13.10a), it can be seen that the "plastic" process is more and more favored as $\sigma_{\mathrm{y}}$ is lower and lower and thus as $T_{\mathrm{g}}$ is lower and lower.

\subsubsection{Temperature dependence of viscoelasticity of epoxy/amine systems}

Certain authors have claimed that Arrhenius law gives the best representation of network behavior in the glass transition region (Misra et al., 1979), but the majority (Shibayama and Suzuki, 1965; Gerard et al., 1991; Ilavsky et al., 1987; Kaelble, 1973; Montazeri et al., 2012) agree with the fact that the temperature variation of the viscosity (shift factor, $a_{\mathrm{T}}=\eta / \eta_{T_{\mathrm{g}}}$ ) is well represented by the WLF (Williams et al., 1955).

For most of the common linear polymers, $C_{1}$ and $C_{2}$ are not very far from the pseudouniversal values: $C_{1} \approx 17 ; C_{2} \approx 50 \mathrm{~K}$ (Adam and Gibbs, 1965). For dense networks, however, $C_{1}$ and $C_{2}$ can differ considerably from these values, which seems to indicate an interesting influence of cross-linking on these constants. Unfortunately, it is possible to find $C_{1}$ and $C_{2}$ values for networks considerably lower (Gerard et al., 1991) as well as considerably higher (Shibayama and Suzuki, 1965) than pseudouniversal ones. Thus, it appears difficult to make a coherent synthesis of literature data in this domain.

Many studies of structural series of amine cross-linked epoxies in which the variable is the amine/epoxy molar ratio (Morgan, 1985), or the cure conversion for a given amine-epoxy pair (Venditti and Gillham, 1996), or the monoamine/diamine molar ratio for ternary systems (Won et al., 1991), showed that the density and the glassy modulus are decreasing functions of $T_{\mathrm{g}}$. This "anomalous" behavior has been often interpreted in terms of volumetric properties (Morgan, 1985; Venditti and Gillham, 1996). The key idea being that the free-volume fraction is an increasing function of the cross-link density, as there is a free volume interpretation of the WLF relationship starting from Doolittle's work (Doolittle, 1951). The determination of the free-volume fraction, $f_{\mathrm{g}}$, from WLF constants and dilatometric measurements, and the study of its variation with cross-link density (or $T_{\mathrm{g}}$ ) can help to determine this relationship.

For a series of epoxy/amine systems, the shift factors $a_{\mathrm{T}}$ were determined from the classical master curve method (Figure 13.11). $T_{\alpha}(1 \mathrm{~Hz})$ was arbitrarily taken as reference temperature $T_{\mathrm{R}}$. Then $\left(\log a_{\mathrm{T}}\right)^{-1}$ was plotted against $\left(T-T_{\mathrm{R}}\right)^{-1}$. Straight lines with a high correlation coefficient were obtained in all the cases, showing that the materials under study obey the WLF time-temperature equivalence principle. The WLF constants $C_{1}$ and $C_{2}$ were determined from the ordinate intercept $\left(1 / C_{1}\right)$ and the slope $\left(C_{2} / C_{1}\right)$ of the straight lines. Their values are listed in Table 13.5. $C_{1}$ and $C_{2}$ appear to be almost proportional; the average value of the ratio $C_{2} / C_{1}$ being about $3.5 \mathrm{~K}$. In the case of DGEBA systems, $C_{2}$ and $C_{1}$ are maximum at $r=0.9$ and decrease sharply on both sides of this value. In the case of TGAP systems, $C_{1}$ and $C_{2}$ are decreasing functions of the aniline content. 


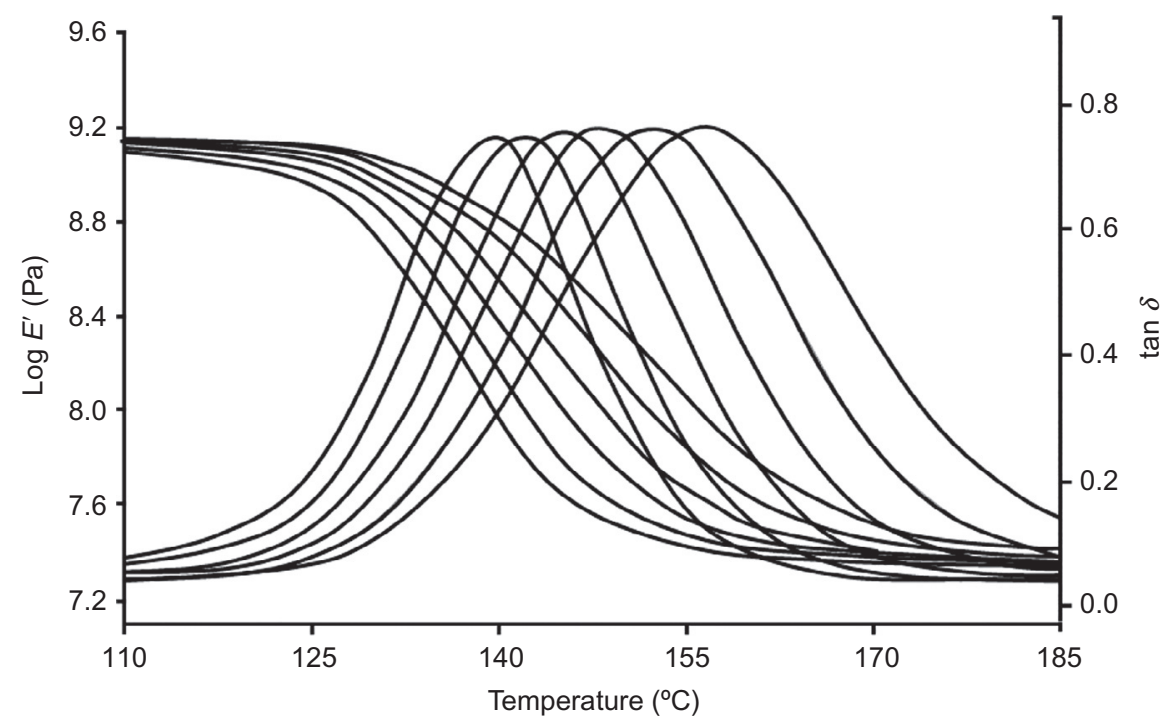

Figure 13.11 Variation of $E^{\prime}$ and $\tan \delta$ with temperature for different frequencies from 0.1 to $200 \mathrm{~Hz}$ (DGEBA/DDM, $A / E=1.1)$.

Source: Tcharkhtchi et al. (1998).

Table 13.5 Network characteristics, transition temperature taken at the maximum of the dissipation peak for $1 \mathrm{~Hz}$ frequency, and WLF constants determined with $T_{\alpha}(1 \mathrm{~Hz})$ as reference temperature

\begin{tabular}{|l|l|l|l|l|l|l|}
\hline System & $\boldsymbol{r}$ & $\begin{array}{l}\boldsymbol{n} \\
\left(\mathbf{m o l ~ k g} \mathbf{~ k g}^{-\mathbf{1}}\right)\end{array}$ & $\begin{array}{l}\boldsymbol{M}_{\mathbf{c}} \\
\left(\mathbf{g} \mathbf{~ m o l}^{-\mathbf{1}}\right)\end{array}$ & $\begin{array}{l}\boldsymbol{T}_{\boldsymbol{\alpha}} \\
(\mathbf{1 ~ H z})\end{array}$ & $\boldsymbol{C}_{\mathbf{1}}$ & $\boldsymbol{C}_{\mathbf{2}}(\mathbf{K})$ \\
\hline DGEBA-DDM & 0.7 & 0.22 & 3030 & 372 & 5.9 & 23.0 \\
DGEBA-DDM & 0.8 & 0.87 & 766 & 393 & 9.3 & 28.1 \\
DGEBA-DDM & 0.9 & 1.49 & 447 & 416 & 12.3 & 51.1 \\
DGEBA-DDM & 1.0 & 2.09 & 319 & 436 & 8.4 & 33.2 \\
DGEBA-DDM & 1.1 & 1.59 & 418 & 419 & 4.5 & 19.3 \\
DGEBA-DDM & 1.2 & 1.23 & 542 & 407 & 4.5 & 16.3 \\
TGAP-AN & - & 2,41 & 276 & 393 & 6.4 & 19.8 \\
TGAP-AN-DDM & - & 4,16 & 160 & 442 & 6.2 & 26.9 \\
TGAP-DDM & - & 5,88 & 113 & 499 & 12.3 & 43.1 \\
\hline
\end{tabular}

\subsubsection{WLF constants}

The proportionality between $C_{1}$ and $C_{2}$ seems to be a general property as relative reported for linear polymers by Adam and Gibbs (1965), for epoxy-amine stoichiometric systems, by Gerard et al. (1991), and for cross-linked polyesters by Shibayama and Suzuki (1965). $C_{1}$ and $C_{2}$ tend to increase with the cross-link density in all these 
series. The fact that there are distinct results for DGEBA (epoxy excess), DGEBA (amine excess), and TGAP systems, and that $C_{1}$ and $C_{2}$ are maximum at $r=0.9$ rather than 1.0 in DGEBA systems indicates that factors other than the cross-link density are also involved. For instance, chains, stiffness is higher in DGEBA than in TGAP systems; dangling chains exist only in DGEBA systems having $r<1$, and so forth.

The results obtained by Gerard et al. and by the authors are, however, somewhat paradoxical as $C_{1}$ and $C_{2}$ increase with the cross-link density but, at the same time, they are lower than the values characteristic of linear polymers $\left(C_{1} \approx 17\right.$, $C_{2} \approx 50 \mathrm{~K}$ ). In other words, the closer the network structure is to a linear polymer, the larger the difference between its WLF constants and pseudouniversal ones. This is not the case for Shibayama and Suzuki's results, for which the values of $C_{1}$ and $C_{2}$ are logically close to pseudouniversal values for low cross-link densities, and increase with the latter.

A simple explanation of the apparent anomaly observed for epoxies can be tentatively proposed: It is based on the arbitrary choice of $T_{\alpha}(1 \mathrm{~Hz})$ as $T_{\mathrm{g}}$ in both the abovereported cases, whereas Shibayama and Suzuki used a $T_{\mathrm{g}}$ value determined from volumetric properties. Considering the results of Table 13.6, it can be reasonably assumed that a more consistent set of data would be obtained taking $T_{\alpha}$ at a considerably lower frequency and, thus, shifting $C_{1}$ and $C_{2}$ toward values higher than those of linear polymers.

The proportionality between $C_{1}$ and $C_{2}$ carries interesting consequences:

(a) WLF equation will have only one constant, $C$ :

$$
\log a_{\mathrm{T}}=\frac{-C\left(T-T_{\mathrm{g}}\right)}{3.5 C+\left(T-T_{\mathrm{g}}\right)}
$$

(b) The apparent activation energy at $T_{\mathrm{g}}$ depends only on $T_{\mathrm{g}}$ :

$$
\left[\frac{\mathrm{d} \operatorname{Ln} a_{\mathrm{T}}}{\mathrm{d}(1 / T)}\right]_{T_{\mathrm{g}}}=-\frac{E_{\text {act }}}{R}=-\frac{2.3 C_{1}}{C_{2}} T_{\mathrm{g}}^{2}=-0.67 T_{\mathrm{g}}^{2}, \quad E_{\mathrm{act}} \approx 5.6 T_{\mathrm{g}}^{2}
$$

Indeed, these relationships are valid only for rough estimations owing to the relatively high dispersion of $C_{2} / C_{1}$ ratios.

Table 13.6 Transition temperature $T_{\alpha}$ at $0.1 \mathrm{~Hz}$ and corresponding WLF constants for different DGEBA-DDM systems

\begin{tabular}{|l|l|l|l|l|}
\hline System & $\boldsymbol{r}$ & $\boldsymbol{T}_{\boldsymbol{\alpha}}(\mathbf{0 . 1} \mathbf{~ H z})$ & $\boldsymbol{C}_{\mathbf{1}}$ & $\boldsymbol{C}_{\mathbf{2}}(\mathbf{K})$ \\
\hline DGEBA-DDM & 0.7 & 368 & 6.5 & 19.2 \\
DGEBA-DDM & 0.8 & 389 & 9.9 & 35.8 \\
DGEBA-DDM & 0.9 & 412 & 17.2 & 66.0 \\
DGEBA-DDM & 1.0 & 432 & 9.6 & 29.5 \\
DGEBA-DDM & 1.1 & 415 & 5.4 & 16.3 \\
DGEBA-DDM & 1.2 & 403 & 5.2 & 15.1 \\
\hline
\end{tabular}




\subsubsection{Free-volume characteristics}

Let us recall that in the framework of the free-volume theory

$$
C_{1}=\frac{B}{2.3 f_{\mathrm{g}}} \text { and } C_{2}=\frac{f_{\mathrm{g}}}{\Delta \alpha}
$$

where $B$ is a constant generally considered close to unity, $f_{\mathrm{g}}$ is the free-volume fraction at $T_{\mathrm{g}}$, and $\Delta \alpha$ is the coefficient of free-volume expansion; thus, the proportionality between $C_{1}$ and $C_{2}$ can be ascribed

$$
\frac{C_{2}}{C_{1}}=3.5 \mathrm{~K}=\frac{2.3 \cdot f_{\mathrm{g}}^{2}}{B \cdot \Delta \alpha} \text { thus } f_{\mathrm{g}}^{2}=1.5 \cdot B \cdot \Delta \alpha
$$

Cross-linking reduces the thermodynamic gap between the glassy and rubbery states because it reduces the number of network configurations available at $T>T_{\mathrm{g}}$. Thus, $\Delta \alpha$ is expected to be a decreasing function of the cross-linking density, as observed here and in other structural series (Shibayama and Suzuki, 1965; Adam and Gibbs, 1965). The result carries the following consequence if the free-volume theory is valid:

(i) The glass transition of networks cannot be considered as an isovolume point. Thus, $T_{\mathrm{g}}$-cross-link density relationships based on this assumption are not valid.

(ii) Many authors have observed that in certain structural series, the density and glassy modulus are decreasing functions of the cross-link density (Morgan, 1985; Venditti and Gillham, 1996; Won et al., 1990, 1991).

This somewhat paradoxical behavior has been explained by the fact that the freevolume fraction would be an increasing function of the cross-link density because, schematically, cross-links create steric hindrances disfavoring a close packing of the network in glassy state. Indeed, this interpretation would be difficult to conciliate with our results indicating that the free-volume fraction is a decreasing function of the cross-link density.

These considerations are, however, valid only if the free-volume theory is itself valid, but is this the case? From the above relationships, it can be written

$$
\Delta \alpha \cdot C_{1} \cdot C_{2}=\frac{B}{2.3} \Rightarrow \Delta \alpha \cdot C^{2}=\frac{B}{8}
$$

where $C=C_{1}=3.5 C_{2}$.

If $B$ is a constant, this relationship involves that $\Delta \alpha$ and $C$ vary in the opposite way, as effectively observed, but it involves also that the relative variations of $\Delta \alpha$ and $C$ with the structure are of the same order of magnitude:

$$
\frac{\mathrm{d}(\Delta \alpha)}{\Delta \alpha}=-2 \frac{\mathrm{d} C}{C}
$$

In fact, it can be seen that $\Delta \alpha \cdot C_{1}^{2}$ varies considerably with the network structure (Table 13.7). This result can be considered as an argument against the free-volume 
Table 13.7 Expansion coefficients and product $\Delta \alpha \cdot C^{2}$ for the samples under study

\begin{tabular}{|l|l|l|l|l|l|}
\hline System & $\boldsymbol{r}$ & $\begin{array}{l}\boldsymbol{\alpha}_{\mathbf{g}} \times \mathbf{1 0}^{\mathbf{4}} \\
\left(\mathbf{K}^{-\mathbf{1}}\right)\end{array}$ & $\begin{array}{l}\boldsymbol{\alpha}_{\mathbf{1}} \times \mathbf{1 0}^{\mathbf{4}} \\
\left(\mathbf{K}^{-\mathbf{1}}\right)\end{array}$ & $\begin{array}{l}\mathbf{\Delta} \times \times \mathbf{1 0}^{\mathbf{4}} \\
\left(\mathbf{K}^{-\mathbf{1}}\right)\end{array}$ & $\begin{array}{l}\boldsymbol{\Delta \alpha} \cdot \mathbf{C}_{\mathbf{1}}^{\mathbf{2}} \times \mathbf{1 0}^{\mathbf{2}} \\
\left(\mathbf{K}^{-\mathbf{1}}\right)\end{array}$ \\
\hline DGEBA-DDM & 0.7 & 1.55 & 4.56 & 3.01 & 1.05 \\
DGEBA-DDM & 0.8 & 1.71 & 4.35 & 2.64 & 2.28 \\
DGEBA-DDM & 0.9 & 1.75 & 4.35 & 2.60 & 3.93 \\
DGEBA-DDM & 1.0 & 1.62 & 4.26 & 2.64 & 1.86 \\
DGEBA-DDM & 1.1 & 1.59 & 4.44 & 2.85 & 0.58 \\
DGEBA-DDM & 1.2 & 1.69 & 4.34 & 2.64 & 0.53 \\
TGAP-AN & - & 1.35 & 3.99 & 2.64 & 1.08 \\
TGAP-AN-DDM & - & 1.71 & 4.05 & 2.34 & 0.90 \\
TGAP-DDM & - & 1.51 & 4.65 & 3.14 & 4.75 \\
\hline
\end{tabular}

theory. The latter could be in principle "saved" in the case where $B$ would be a function of the cross-link density, but with an increased number of adjustable parameters, the WLF relationship would lose most of its practical interest.

\subsubsection{Modeling of viscoelastic properties of epoxy networks in the glass transition region}

The major difference between a thermoset and a thermoplastic polymer is molecular structure. In fact, the properties of thermosets depend on the effect of the cross-linking on the relaxation spectrum. As a matter of fact, chain motions must be perturbed in the immediate vicinity of cross-links. Thus, if the width of the relaxation spectrum expresses the diversity of the situation of chain segments, it is expected to be higher in tridimensional than in linear polymers. The best way to obtain information on the relaxation spectra is dynamical testing and study of complex modulus, $G^{*}$ in frequency domain from Cole-Cole plots $\left(G^{\prime}=f\left(G^{\prime \prime}\right)\right.$. A study has been performed on a series of epoxy/amines (DGEBA/DDM) samples with various amine/epoxy molar ratios (Table 13.8; Tcharkhtchi et al., 1998, 1999).

Table 13.8 Characteristics of networks under study

\begin{tabular}{|l|l|l|l|l|l|l|}
\hline$A / E^{\mathrm{a}}$ & 0.7 & 0.8 & 0.9 & 1.0 & 1.1 & 1.2 \\
$\left.X(\mathrm{~mol} \mathrm{~kg})^{-1}\right)^{\mathrm{b}}$ & 0.22 & 0.87 & 1.49 & 2.09 & 1.59 & 1.23 \\
$T_{\mathrm{g}}(\mathrm{K})^{\mathrm{c}}$ & 378 & 398 & 416 & 436 & 420 & 411 \\
$E_{\max }(\mathrm{MPa})^{\mathrm{d}}$ & 245 & 220 & 200 & 190 & 210 & 235 \\
\hline
\end{tabular}

\footnotetext{
a Amine/epoxide molar ratio.

b Cross-linked density expressed in moles of network nodes per kg calculated according to Tcharkhtchi et al. (1998).

${ }^{c} T_{\mathrm{g}}$ taken at the maximum of $E^{\prime \prime}$ for $1 \mathrm{~Hz}$ frequency.

${ }^{\mathrm{d}}$ For $1 \mathrm{~Hz}$ frequency.
} 

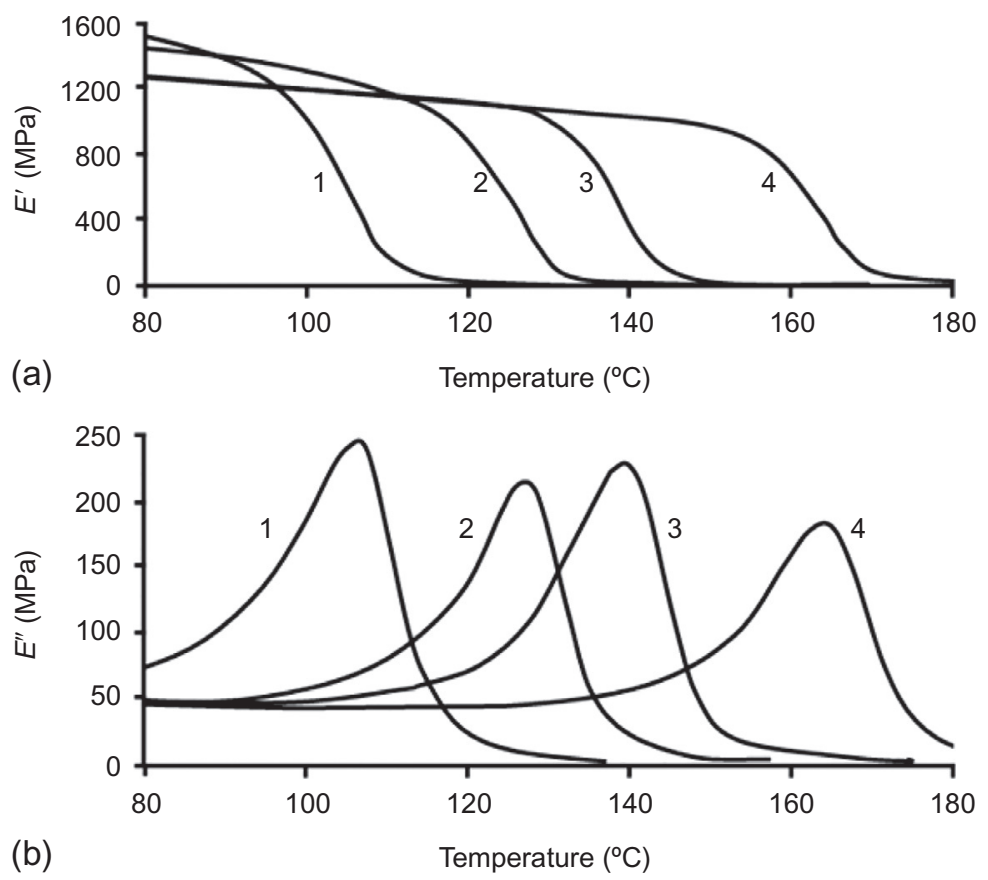

Figure 13.12 Variation of $E^{\prime}$ (a) and $E^{\prime \prime}$ (b) with temperature for different $A / E(f=1 \mathrm{~Hz})$. (1) $A / E=0.7$, (2) $A / E=0.8$, (3) $A / E=1.2$, and (4) $A / E=1.0$.

Source: Tcharkhtchi et al. (1998).

The experimental curves $G^{\prime}, \tan \delta$, and $G^{\prime \prime}$ versus temperature for various frequencies and for various $A / E$ are obtained by DMTA tests, shown in Figure 13.12.

As expected, $T_{\mathrm{g}}$ is maximum and $G^{\prime \prime}$ is minimum at the stoichiometric point, which corresponds to the maximum cross-linked density.

Cole-Cole plots are shown in Figure 13.13. A single curve is obtained in all frequencies $(0.1-200 \mathrm{~Hz})$ for $A / E=0.9$ and 1.2 where some scatter is observed in the high-modulus domain. The relaxed, $G_{0}$, and unrelaxed, $G_{\propto}$, moduli were then determined. $G_{0}$ (rubbery modulus) is graphically determined. Its values carry strong uncertainties but they do not have significant effect on the model parameters. $E_{\propto}$ is determined by linear extrapolation from glassy state points, using the best compromise between the broadness of the modulus range and the value of the correlation coefficient.

Havriliak-Negami (HN)'s model (Havriliak and Negami, 1967) was used to represent the complex modulus variation:

$$
G^{*}=G_{\infty}-\frac{G_{\infty}-G_{0}}{\left[1+(\mathrm{i} \omega \tau)^{(1-\alpha)}\right]^{\gamma}}
$$

This model fits the experimental curves within experimental uncertainties (Figure 13.11). The corresponding parameters are given in Table 13.9. 

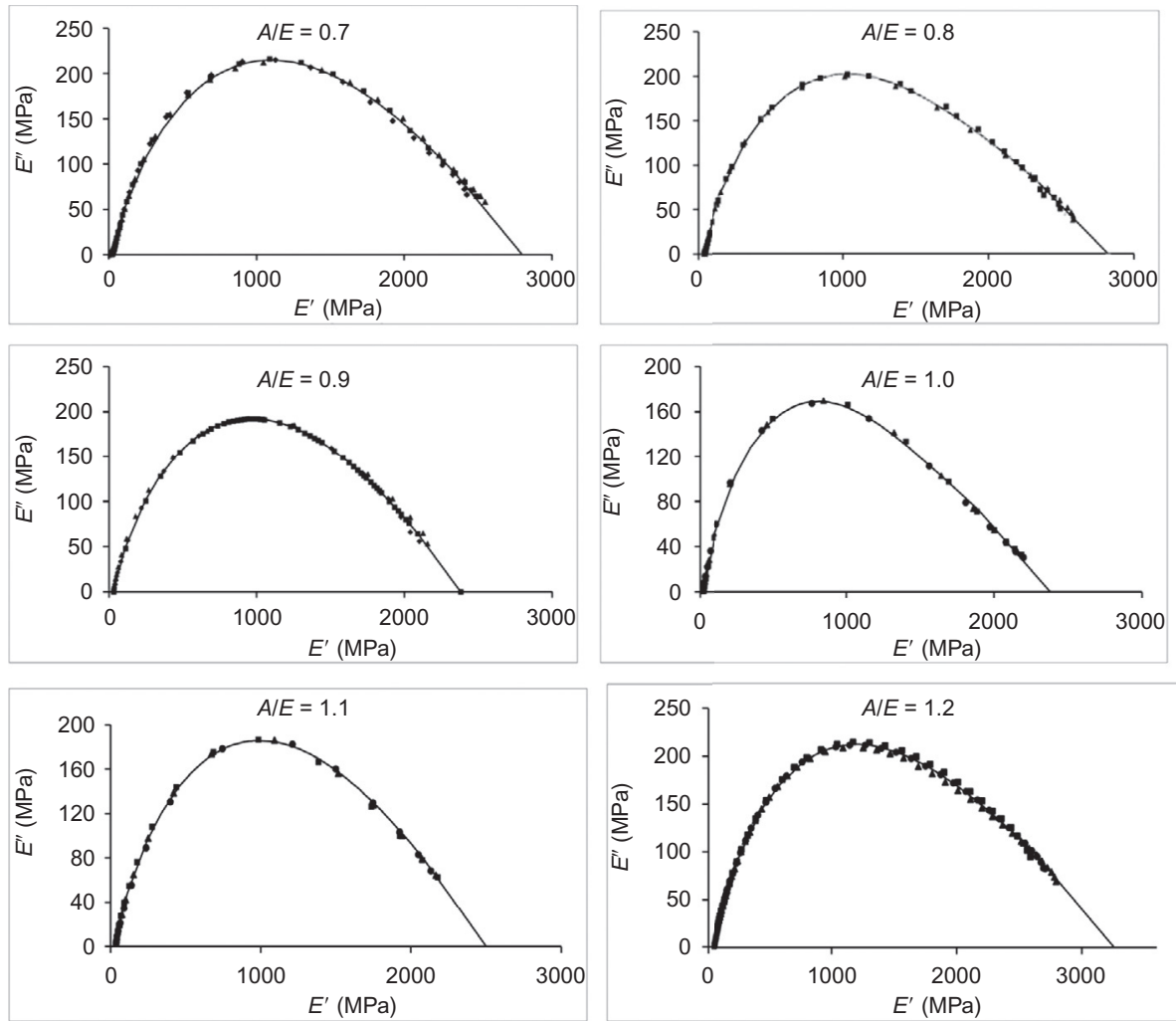

Figure 13.13 Cole-Cole plots for the samples under study. Points: experimental data, line: models, both models are practically undistinguishable.

Source: Tcharkhtchi et al. (1998).

Table 13.9 Parameters of HN models obtained for different epoxy systems

\begin{tabular}{|l|l|l|l|l|}
\hline \multirow{2}{*}{$\boldsymbol{A} / \boldsymbol{E}$} & & & \multicolumn{2}{|c|}{ HN's model } \\
\cline { 4 - 5 } & $\boldsymbol{E}_{\mathbf{0}}(\mathbf{M P a})$ & $\boldsymbol{E}_{\propto}(\mathbf{M P a})$ & $\boldsymbol{\alpha}$ & $\boldsymbol{\gamma}$ \\
0.7 & 14 & 2900 & 0.430 & 0.355 \\
0.8 & 30 & 2820 & 0.445 & 0.355 \\
0.9 & 10 & 2520 & 0.405 & 0.330 \\
1.0 & 12 & 2440 & 0.400 & 0.280 \\
1.1 & 6 & 2520 & 0.475 & 0.410 \\
1.2 & 30 & 3400 & 0.410 & 0.260 \\
\hline
\end{tabular}


These results call for the following comments:

(i) No trend appears in $G_{0}$ values owing to their high scatter. They are expected to be maximum at the stoichiometric point. Values are minimum $G_{\propto}$ at the stoichiometric point as a result of an internal antiplasticization effect (Findley and Reed, 1977; Morgan, 1985; Bellenger et al., 1996; Venditti and Gillham, 1996).

(ii) In a first approach, it could be observed that the parameters of the models, except $G_{0}$ and $G_{\propto}$, are almost independent of the structure. Thus, the network behavior would depend on $T_{\mathrm{g}}$ and on $G_{\propto}$ but the characteristics linked to the relaxation spectrum, essentially expressed by the exponents $\alpha$ and $\beta$, would be almost constant.

(iii) From numerical applications, it can easily be shown that variations of these exponents lower than the observed intervals, for instance $\Delta \alpha$ or $\Delta \gamma=0.01$ for the HN function, lead to noticeable modifications of the shape of Cole-Cole plots. In other words, the variations of $\alpha, \beta$ are significant. The variations of these parameters with the network structure can be tentatively analyzed.

(iv) It appears that $\alpha$ and $\gamma$ are more or less interrelated and tend to decrease when the cross-link density increases in both sides of the stoichiometric point. According to Alvarez et al. (1991), in the range where $(1-\alpha)>0.40$ and $\gamma>0.25$, the HN function is the counterpart of the Kolrausch-Williams-Wutt (KWW) function in the time domain $G_{\mathrm{t}}=G_{0}+\left(G_{\infty}-G_{0}\right) \exp \left[-\left(\frac{t}{\tau}\right)^{\beta}\right]$

where $\tau$ is an average relaxation time, and $\beta$ is the KWW parameter linked to the width of the relaxation spectrum. Thus, each pair of $\alpha$ and $\gamma$ HN parameters would correspond to one and only one $\beta$, KWW parameter value. Despite the fact that its generalization is questionable, the approach of Alvarez et al. opens the way to a simple expression of the static or monotone mechanical behavior of the networks under study. In terms of relaxation spectra, the fact that $\alpha, \gamma$, and $(1-\alpha) \gamma$ are decreasing functions of the cross-link density seems to indicate that cross-linking induces a broadening of relaxation spectrum.

In conclusion, the viscoelastic properties of DGEBA-DDM networks of amine/ epoxide ratio ranging from 0.7 to 1.2 and having cross-link densities from 0.2 to $2 \mathrm{~mol} \mathrm{~kg}{ }^{-1}\left(M_{\mathrm{c}}\right.$ between 300 and $\left.320 \mathrm{~g} \mathrm{~mol}^{-1}\right)$ have been studied in the glass transition region. They are well fitted by the $\mathrm{HN}$ model. The parameters linked to the distribution of relaxation time do not vary much with the structure. However, a significant decrease of $\alpha$ and $\gamma$ with the cross-link density has been observed.

\section{References}

Adam, G., Gibbs, J.H., 1965. On the Temperature Dependence of Cooperative Relaxation Properties in Glass-Forming Liquids. J. Chem. Phys. 43 (1), 139-146.

Aizpurua, B., Franco, M., Corcuera, M.A., Riccardi, C.C., Mondragon, I., 2000. Chemorheology and ultimate behavior of epoxy-amine mixtures modified with a liquid oligomer. J. Appl. Polym. Sci. 76, 1269-1279.

Alvarez, F., Algeria, A., Colmenero, J., 1991. Relationship between the time-domain Kohlrausch-Williams-Watts and frequency-domain Havriliak-Negami relaxation functions. J. Phys. Rev. B. 44 (11), 7306. 
Bellenger, V., Dhaoui, W., Verdu, J., Boye, J., Lacabanne, C., 1990. Internal antiplasticization in diglycidyl ether of bisphenol A diamino diphenyl methane non-stoichiometric epoxy networks, Polym. Eng. Sci. 30. Issue 6, 321-325.

Bellenger, V., Dhaoui, W., Verdu, J., Boye, J., Lacabanne, C., 1996. Polym. Eng. Sci. 30, 321.

Bidstrup, S.A., Macosko, C.W., 1990. Chemorheology relations for epoxy-amine crosslinking, J. Polym. Sci. Part B 28, 691-709.

Bonnet, A., Pascault, J.P., Sautereau, H., Camberlin, Y., 1999. Epoxy-Diamine Thermoset/ Thermoplastic Blends. 2. Rheological Behavior before and after Phase Separation, Macromolecules 32, 8524-8530.

Castro, J.M., Macosko, C.W., 1980. Kinetics and rheology of typical polyurethane reaction injection molding. SPE Technical Papers 26, 434.

Castro, J.M., Macosko, C.W., 1982. Studies of mold filling and curing in the reaction injection molding process. AICHE J. 28, 250.

Chang, T.D., Brittain, J.O., 1982. Studies of epoxy resin systems: Part D: fracture toughness of an epoxy resin: a study of the effect of crosslinking and sub-Tg aging. Polym. Eng. Sci. 22 (18), 1228.

Charleswort, J., 1980. An analysis of the substitution effects involved in diepoxide-diamine copolymerization reactions. J. Polym. Sci. Polym. Chem. Ed. 18 (2), 621-628.

Chiou, P.L., Letton, A., 1992. Modelling the chemorheology of an epoxy resin system exhibiting complex curing behavior. Polymer 33, 3925-3931.

Cioffi, M., Ganzeveld, K.J., Hoffmann, A.C., Janssen, L.P.B.M., 2002. Rheokinetics of linear polymerization. A literature review. Polym. Eng. Sci. 42, 2383.

Corezzi, S., Fioretto, D., Santucci, G., Kenny, J.M., 2010. Modeling diffusion-control in the cure kinetics of epoxy-amine thermoset resins: an approach based on configurational entropy. Polymer 51 (24), 5833-5845.

Cox, W.P., Merz, E.H., 1958. Correlation of dynamic and steady flow viscosities. J. Polym. Sci. $28,619-622$.

Dai-Soo Lee, C.D.H., 1987. A chemorheological model for the cure of unsaturated polyester resin. Polym. Eng. Sci. 27, 955-963.

de Gennes, P.G., 1991. Scaling Concepts in Polymer Physics. Cornell Univ. Press, Ithaca. NY.

Doolittle, A.K., 1951. Studies in Newtonian flow: I. The dependence of the viscosity on temperature. J. Appl. Phys. 22 (1031), 1471.

Dušek, K., 1986. Network Formation in Curing of Epoxy Resins, vol. 78. Advances in Polymer Science. Springer-Verlag, Berlin/Heidelberg.

Enns, J.B., Gillham, J.K., 1983. Time-temperature-transformation (TTT) cure diagram: modeling the cure behavior of thermosets. J. Appl. Polym. Sci. 28, 2567.

Findley, W.N., Reed, R.M., 1977. Effect of cross-linking on hydrostatic creep of epoxy. Polym. Eng. Sci. 27, 837-841.

Fischer, M., 1988. Failure of glassy polymers with tailored distances between cross-links. In: Paper 1.16 Presented at the 20th Europhysics Conference on Macromolecular Physics, Lausanne, September 26-30.

Flammersheim, H.J., 1998. Kinetics and mechanism of the epoxide-amine polyaddition. Thermochim. Acta 310, 153-159.

Gerard, J.F., Galy, J., Pascault, J.P., Cukierman, S., Halary, J.L., 1991. Viscoelastic response of model epoxy networks in the glass transition region. Polym. Eng. Sci. 31 (8), 615-621.

Girard-Reydet, E., Riccardi, C.C., Pascault, J.P., 1995. Epoxy-aromatic diamine kinetics. Part 1. Modeling and influence of the diamine structure. Macromolecules 28 (23), 7599-7607. 
Grillet, A.C., Galy, J., Gerard, J.F., Pascault, J.P., 1991. Mechanical and viscoelastic properties of epoxy networks cured with aromatic diamines. Polymer 32, 1885-1891.

Havriliak, S., Negami, S., 1967. Complex plane representation of dielectric and mechanical relaxation processes in some polymers. Polymer 8, 161-210.

Horie, K., Hiura, H.S.M., Mita, I., Kambe, H., 1970. Calorimetric investigation of polymerization reactions. III. Curing reaction of epoxides with amines. J. Polym. Sci. A-1 (8), 1357.

Ilavsky, M., Hrouz, J., Havlicek, I., 1987. In: Sedlecek, B., Kahoved, J. (Eds.), Cross-Linked Epoxies. W de Gruyter, Berlin, p. 425.

Kaelble, D.H., 1973. In: May, C.A., Tanaka, Y. (Eds.), Epoxy Resins. Marcel Dekker, New York.

Kambour, R.P., 1983. Correlations of the dry crazing resistance of glassy polymers with other physical properties. Polym. Commun. 24, 292.

Kambour, R.P., Farraye, E.A., 1984. Crazing beneath notches inducitle polymers: a materials correlation. Polym. Commun. 25, 357.

Kinloch, A.J., 1985. Mechanics and mechanisms of fracture of thermosetting epoxy polymers. Adv. Polym. Sci. 72 (1), 45.

Kroutilova, I., Matejka, L., Sikora, A., Soucek, K., Stag, L., 2006. Curing of epoxy systems at sub-glass transition temperature. J. Appl. Polym. Sci. 99, 3669-3676.

Lemay, J.D., Kelley, F.N., 1986. Structure and ultimate properties of epoxy resins. Adv. Polym. Sci. 78, 116.

Lipshitz, S.D., Macosko, C.W., 1976. Rheological changes during a urethan network polymerization. Polym. Eng. Sci. 16, 803.

Liu, H., Uhlherr, A., Varley, R.J., Bannister, M.K., 2004. Influence of substituents on the kinetics of epoxy/aromatic diamine resin systems. J. Polym. Sci. A Polym. Chem. $42,3143$.

Macosko, C.W., 1985. Rheological changes during crosslinking. Br. Polym. J. 17, 239-245.

Matejka, L., 2000. Amine cured epoxide networks: formation, structure, and properties. Macromolecules 33, 3611-3619.

Matejka, L., Dusek, K., 1989. Mechanism and kinetics of curing of epoxides based on diglycidylamine with aromatic amines. 2 . The reaction between diglycidylaniline and aniline. Macromolecules 22, 2911-2917.

Mezzenga, R., Boogh, L., MaǏšnson, J.A.E., Pettersson, B., 2000. Effects of the branching architecture on the reactivity of epoxy-amine groups. Macromolecules 33, 4373.

Mijovic, J.L., 1989. Modeling of chemorheology of thermoset cure by modified WLF equation. J. Appl. Polym. Sci. 37, 889-900.

Mijovic, J., Ott, J., 1989. Modeling of chemorheology of an amine-epoxy system of the type used in advanced composites. J. Compos. Mater. 23, 163.

Mijovic, J., Fishbain, A., Wijaya, J., 1992. Mechanistic modeling of epoxy-amine kinetics. 1. Model compound study. Macromolecules 25, 979-985.

Miller, D.R., Macosko, C.W., 1978. Average property relations for nonlinear polymerization with unequal reactivity. Macromolecules 11, 656-662.

Miller, D.R., Macosko, C.W., 1980. Polymerization. Macromolecules 13, 1063.

Miller, D.R., Valles, E.M., Macosko, C.W., 1979. Calculation of molecular parameters for stepwise polyfunctionai polymerization. Polymer 19, 273.

Misra, S.C., Manson, J.A., Sperling, L.H., 1979. Epoxy resins Chemistry. ACS Sym. Series 114, 137.

Montazeri, A., Pourshamsian, K., Riazian, M., 2012. Viscoelastic properties and determination of free volume fraction of multiwalled carbon nanotube/epoxy composite using dynamic mechanical thermal analysis. Mater. Des. 36, 408-414. 
Morgan, R.G., 1985. Structure-property relations of epoxies used as composite matrices. Adv. Polym. Sci. 72, 1-43.

Mounif, E., Bellenger, V., Tcharkhtchi, A., 2008. Time-temperature-transformation (TTT) diagram of the isothermal crosslinking of an epoxy/amine system: curing kinetics and chemorheology. J. Appl. Polym. Sci. 108 (5), 2908-2916.

Mounif, E., Bellenger, V., Mazabraud, P., Nony, F., Tcharkhtchi, A., 2010. Chemorheological study of DGEBA/IPD system for reactive rotational molding (RRM). J. Appl. Polym. 116 (2), 969-976.

Pascault, J.P., Williams, R.J.J., 1990. Glass transition temperature versus conversion relationships for thermosetting polymers. J. Polym. Sci. B 28, 85-95.

Pascault, J.P., Sautereau, H., Verdu, J., Williams, R., 2002. Thermosetting Polymers. Marcel Dekker, Basel.

Paz-Abuin, S., Lopez-Quintela, A., Varela, M., Pazos-Pellin, M., Prendes, P., 1997a. Method for determination of the ratio of rate constants, secondary to primary amine, in epoxyamine systems. Polymer 38, 3117-3120.

Paz-Abuin, S., Pellin, M.P., Paz-Pazos, M., Quintela, A.L., 1997b. Influence of the reactivity of amine hydrogens and the evaporation of monomers on the cure kinetics of epoxy-amine: kinetic questions. Polymer 38, 3795-3804.

Prolongo, S.G., Mikes, F., Cabanelas, J.C., Paz-Abuin, S., Baselga, J., 2003. Diffusion control on the cure kinetics of DGEBA with ethylenediamines. J. Mater. Process. Technol. 143, 546-550.

Ramos, J.A., Pagani, N., Riccardi, C.C., Borrajo, J., Goyanes, S.N., Mondragon, I., 2005. Cure kinetics and shrinkage model for epoxy-amine system. Polymer 46, 3323-3328.

Riccardi, C.C., Fraga, F., Dupuy, J., Williams, R.J.J., 2001. Cure kinetics of diglycidylether of bisphenol A—ethylenediamine revisited using a mechanistic model. J. Appl. Polym. Sci. 82, 2319-2325.

Roller, M.B., 1986. Rheology of curing thermosets: a review. Polym. Eng. Sci. 26, 432-440.

Rozenberg, B.A., 1986. Epoxy Resins and Composites. II, vol. 75. Advances in Polymer Science. Springer-Verlag, New York, Berlin, 113-165.

Shibayama, K., Suzuki, Y., 1965. Effect of crosslinking density on the viscoelastic properties of unsaturated polyesters. J. Polym. Sci. A 3, 2637-2651.

Smith, I.T., 1961. The mechanism of the cross-linking of epoxide resins by amines. Polymer 2, 95-108.

Tajima, Y.A., Crozier, D.G., 1986. Chemorheology of an amine-cured epoxy resin. Polym. Eng. Sci. 26, 427-431.

Tajima, Y.A., Crozier, D.G., 1988. Chemorheology of an epoxy resin for pultrusion. Polym. Eng. Sci. 28, 491-495.

Tcharkhtchi, A., Lucas, A.S., Trotignon, J.P., Verdu, J., 1998. Viscoelastic properties of epoxy networks in the glass transition region. Polymer 39 (5), 1233-1235.

Tcharkhtchi, A., Trotignon, J.P., Verdu, J., 1999. Yielding and fracture in cross-linked epoxide. In: Mechanical Behaviour of Polymeric Materials, IUPAC. Macromolecular Symposia, vol. 147. WILEY-VCH, pp. 221-234.

Urbaczewski-Espuche, E., Galy, J., Gerard, J.F., Pascault, J.P., Sautereau, H., 1991. Influence of chain flexibility and crosslink density on mechanical properties of epoxy/amine networks. Polym. Eng. Sci. 31, 1572.

Valles, E.M., Macosko, C.W., 1979. Structure and viscosity of poly(dimethylsiloxanes) with random branches. Macromolecules 12, 521-526.

Venditti, R.A., Gillham, J.K., 1996. Anomalous behavior of thermosetting systems after cure vs. chemical conversion: a normalized conversion-temperature-property diagram. J. Appl. Polym. Sci. 56, 1687-1705. 
Wang, Q., He, T., Xia, P., Chen, T., Huang, B., 1997. Cure processing modeling and cure cycle simulation of epoxy-terminated poly(phenylene ether ketone). II. Chemorheological modeling. J. Appl. Polym. Sci. 66, 799-808.

Williams, M.L., Landel, R.F., Ferry, J.D., 1955. The temperature dependence of relaxation mechanisms in amorphous polymers and other glass-forming liquids. J. Am. Chem. Soc. 77, 3701-3707.

Wise, C.W., Cook, W.D., Goodwin, A.A., 1997. Chemico-diffusion kinetics of model epoxyamine resins. Polymer 38, 3251-3261.

Won, Y.G., Galy, J., Gerard, J.F., Pascault, J.P., Bellenger, V., Verdu, J., 1990. Internal antiplasticization in copolymer and terpolymer networks based on diepoxides, diamines and monoamines. Polymer 31, 1787-1792.

Won, Y.G., Galy, J., Pascault, J.P., Verdu, J., 1991. Prediction of the glass transition temperature of cycloaliphatic amine-epoxy networks. J. Polym. Sci. Polym. Phys. Ed. 29, 981-987.

Wu, S., 1989. Chain structure and entanglement. J. Appl. Polym. Sci. Polym. Phys., B 27, 723-741.

Wu, S., 1992. Secondary relaxation, brittle-ductile transition temperature, and chain structure. J. Appl. Polym. Sci. 46, 619-624.

Zimm, B.H., Stockmayer, W.H., 2004. The dimensions of chain molecules containing branches and rings. J. Chem. Phys. 17, 1301. 